LBNL-57339. Preprint. 2005 MRS Spring Meeting, March 28-April 1, 2005, San Francisco, CA

Symposium F: Thin-Film Compound Semiconductor Photovoltaics

\title{
Highly Mismatched Alloys for Intermediate Band Solar Cells
}

W. Walukiewicz ${ }^{1}$, K. M. Yu ${ }^{1}$, J Wu ${ }^{2}$, J. W. Ager III ${ }^{1}$, W. Shan ${ }^{1}$, M. A. Scrapulla ${ }^{1,3}$, and O. D. Dubon ${ }^{1,3}$, and P. Becla ${ }^{4}$

${ }_{1}^{1}$ Materials Sciences Division, Lawrence Berkeley National Laboratory, Berkeley, CA 94720

${ }^{2}$ Department of Chemistry and Chemical Biology, Harvard University, , Cambridge, MA 02138

${ }^{3}$ Department of Materials Science and Engineering, University of California, Berkeley, CA 94720

${ }^{4}$ Department of Materials Science and Engineering, Massachusetts Institute of Technology, Cambridge, Massachusetts 02139

\section{ABSTRACT}

It has long been recognized that the introduction of a narrow band of states in a semiconductor band gap could be used to achieve improved power conversion efficiency in semiconductor-based solar cells. The intermediate band would serve as a "stepping stone" for photons of different energy to excite electrons from the valence to the conduction band. An important advantage of this design is that it requires formation of only a single $p$-n junction, which is a crucial simplification in comparison to multijunction solar cells. A detailed balance analysis predicts a limiting efficiency of more than $50 \%$ for an optimized, single intermediate band solar cell. This is higher than the efficiency of an optimized two junction solar cell. Using ion beam implantation and pulsed laser melting we have synthesized $\mathrm{Zn}_{1-\mathrm{y}} \mathrm{Mn}_{\mathrm{y}} \mathrm{O}_{\mathrm{x}} \mathrm{Te}_{1-\mathrm{x}}$ alloys with $\mathrm{x}<0.03$. These highly mismatched alloys have a unique electronic structure with a narrow oxygen-derived intermediate band. The width and the location of the band is described by the Band Anticrossing model and can be varied by controlling the oxygen content. This provides a unique opportunity to optimize the absorption of solar photons for best solar cell performance. We have carried out systematic studies of the effects of the intermediate band on the optical and electrical properties of $\mathrm{Zn}_{1-\mathrm{y}} \mathrm{Mn}_{\mathrm{y}} \mathrm{O}_{\mathrm{x}} \mathrm{Te}_{1-\mathrm{x}}$ alloys. We observe an extension of the photovoltaic response towards lower photon energies, which is a clear indication of optical transitions from the valence to the intermediate band.

\section{INTRODUCTION}

Efforts to improve the efficiency of solar cells have led to extensive experimental and theoretical studies of new materials and new cell designs. To date, the highest power conversion efficiencies have been achieved with multijunction solar cells based on standard semiconductor materials $(\sim 31 \%)[1,2]$. It was recognized over thirty years ago that the introduction of states in a semiconductor band gap presents an alternative to multijunction designs for improving the power conversion efficiency of solar cells [3]. Detailed theoretical calculations indicated that a single junction cell with a properly located band of intermediate states could achieve power conversion efficiencies up to $62 \%$ - i.e. higher than those for optimized double-junction tandem cells [4-6]. Despite years of intense efforts no multi-band semiconductor material has been realized yet [6].

In this paper, we report the design and synthesis of a new type of material having a narrow band of extended states within a semiconductor band gap. The design of our material is based on the recently introduced band anticrossing (BAC) model of highly mismatched 
semiconductor alloys (HMAs) [7-9]. The BAC model considers compound semiconductor alloys in which metallic anion atoms are partially replaced with more electronegative atoms. Group III-N-V alloys in which group V anions are partially replaced with N [10] or group II-OVI alloys in which column VI element is replaced with O [11] are the well known examples of the HMAs. The electronic structure of the HMAs is determined by the interaction between localized states associated with $\mathrm{N}$ or $\mathrm{O}$ atoms and the extended states of the host semiconductor. As a result the conduction band splits into two subbands $\left(\mathrm{E}_{-}\right.$and $\left.\mathrm{E}_{+}\right)$with non-parabolic dispersion relations [7-9]. For the cases of O in ZnTe, MnTe, the BAC model predicts that the anticrossing interaction of the $\mathrm{O}$ states with the extended conduction band states in the $\mathrm{Zn}_{1 \text { - }}$ ${ }_{\mathrm{y}} \mathrm{Mn}_{\mathrm{y}} \mathrm{Te}$ will lead to the formation of a narrow band of intermediate states [12]. With multiple band gaps that fall within the solar energy spectrum, $\mathrm{Zn}_{1-\mathrm{x}} \mathrm{Mn}_{\mathrm{x}} \mathrm{O}_{\mathrm{y}} \mathrm{Te}_{1-\mathrm{y}}$ is well suited for the proposed high efficiency intermediate band solar cells (IBSCs) [6].

\section{EXPERIMENT}

We have used $\mathrm{O}$ ion implantation followed by pulsed laser melting (PLM) to synthesize $\mathrm{Zn}_{1-\mathrm{x}} \mathrm{Mn}_{\mathrm{x}} \mathrm{O}_{\mathrm{y}} \mathrm{Te}_{1-\mathrm{y}}$ alloys. Multiple energy implantation using 90 and $30 \mathrm{keV} \mathrm{O}^{+}$was carried out on $\mathrm{Zn}_{1-\mathrm{y}} \mathrm{Mn}_{\mathrm{y}} \mathrm{Te}(\mathrm{y}=0$ and 0.12 ) single crystals to form $\sim 0.2 \mu \mathrm{m}$ thick layers with relatively constant $\mathrm{O}$ concentrations corresponding to $\mathrm{O}$ mole fractions of $0.0165-0.044$. The $\mathrm{O}^{+}-$ implanted samples were pulsed-laser melted in air using a $\mathrm{KrF}$ laser $(\lambda=248 \mathrm{~nm})$ with a FWHM pulse duration $\sim 38 \mathrm{~ns}$. The energy fluence at the sample ranged between 0.020 and $0.3 \mathrm{~J} / \mathrm{cm}^{2}$. Some of the samples underwent RTA after the PLM at temperatures between 300 and $700^{\circ} \mathrm{C}$ for 10 seconds in flowing $\mathrm{N}_{2}$. Pulsed laser melting (PLM) is a highly non-equilibrium processing technique $[13,14]$ which involves the rapid melting and recrystallization of the near surface region $(<0.5 \mu \mathrm{m})$ in a time scale of $10^{-8}-10^{-6}$ second. The rapid recrystallization rate results in the incorporation of impurity atoms to a level well above the solubility limit. This combined ion beam and laser processing approach has been demonstrated as an effective approach to synthesize dilute semiconductor alloys including $\mathrm{GaAs}_{1-\mathrm{x}} \mathrm{N}_{\mathrm{x}}$ and $\mathrm{Ga}_{1-\mathrm{x}} \mathrm{Mn}_{\mathrm{x}} \mathrm{As}[15,16]$.

The band gaps of the films were measured using photomodulated reflectance (PR) at room temperature using a chopped $\mathrm{HeCd}$ laser beam $(\lambda=442 \mathrm{~nm}$ or $325 \mathrm{~nm})$ for modulation. PR signals were detected by a Si photodiode using a phase-sensitive lock-in amplification system. The values of the band gap and the line width were determined by fitting the PR spectra to the Aspnes third-derivative functional form [17].

\section{RESULTS AND DISCUSSION}

Fig. 1 shows PR spectra from a $\mathrm{Zn}_{0.88} \mathrm{Mn}_{0.12}$ Te substrate and two $\mathrm{Zn}_{0.88} \mathrm{Mn}_{0.12}$ Te samples implanted with $3.3 \%$ of $O$ followed by PLM with laser energy fluence of 0.15 and $0.3 \mathrm{~J} / \mathrm{cm}^{2}$. Two optical transitions occurring at energies distinctly different from the fundamental band gap transition $E_{M}(=2.31 \mathrm{eV})$ of the $\mathrm{Zn}_{0.88} \mathrm{Mn}_{0.12}$ Te matrix can be clearly observed at $\sim 1.8$ and $2.6 \mathrm{eV}$ from the samples after PLM. These. two optical transitions can be attributed to transitions from the valence band to the two conduction subbands, $E_{+}(\sim 2.6 \mathrm{eV})$ and $E_{-}(\sim 1.8 \mathrm{eV})$ formed as a result of the hybridization of the localized $\mathrm{O}$ states and the extended conduction band states of ZnMnTe. The strong photomodulated transition signals at both $E_{-}$and $E_{+}$indicates the extended 
nature of these electronic states and the substantial oscillator strength for the transitions. No optical transition is observed for the implanted samples with PLM fluence lower than $0.04 \mathrm{~J} / \mathrm{cm}^{2}$ indicating that the melting threshold for $\mathrm{ZnMnTe}$ is between 0.04 and $0.08 \mathrm{~J} / \mathrm{cm}^{2}$.

The BAC model has been successful in quantitatively explaining the band structure modifications induced by a more electronegative element substituting the more metallic anions in both III-V and II- VI compounds (e.g. $\mathrm{N}$ in GaAs and $\mathrm{S}$ in ZnTe) [7-9]. Large reductions in the fundamental bandgap have also been demonstrated in $\mathrm{O}^{+}$-implanted CdMnTe followed by rapid thermal annealing (RTA) [11]. Such band gap reduction can be explained by the optical transition from the valence band to the lower subband $E_{-}$. However, transition to the upper subband in these dilute II-VI oxides (or any other II-VI HMAs [8]) had never been observed. The absence of spectral features related to the optical transition associated with the conduction-band edge $E_{+}$in the $\mathrm{ZnO}_{x} \mathrm{Se}_{1-x}$ [18] and $\mathrm{CdO}_{\mathrm{x}} \mathrm{Te}_{1-\mathrm{x}}[11]$ samples is not inconsistent with the BAC model. Note that in these cases the $E_{+}$ band edge has mostly localized-like character since the localized $E_{O}$ states are located within the conduction band. Since the dipole interaction for optical transitions couples much more strongly to extended states than localized states, the transition related to $E_{+}$is inherently weak. For the case of $\mathrm{ZnO}_{\mathrm{x}} \mathrm{Te}_{1-\mathrm{x}}$ where the $E_{O}$ states lie below the conduction minimum, the $E_{+}$band states are more extended in character and consequently optical transition becomes strong. The transitions at around $2.6 \mathrm{eV}$ are the first observation of the $\mathrm{E}_{+}$subband in II-VI HMAs.

The amount of $\mathrm{O}$ incorporated in the Te sublattice in $\mathrm{Zn}_{0.88} \mathrm{Mn}_{0.12} \mathrm{O}_{\mathrm{x}} \mathrm{Te}_{1-\mathrm{x}}$ HMAs can be determined using the BAC model that relates the two subbands with the incorporated $O$ content [7-9]. Using $E_{O}=2.06 \mathrm{eV}$ as the position of the localized O level in ZnMnTe [18], and 2.2 $\mathrm{eV}$ as the matrix element describing the coupling between localized $E_{O}$ states and the extended states of the host conduction band $E_{M}$. [11,19], we estimate that for the sample after PLM with 0.15 and $0.3 \mathrm{~J} / \mathrm{cm}^{2}$ (as shown in Fig. 1), $\mathrm{x} \sim 0.024$ and 0.018 , respectively. We have also synthesized $\mathrm{Zn}_{0.88} \mathrm{Mn}_{0.12} \mathrm{O}_{\mathrm{x}} \mathrm{Te}_{1-\mathrm{x}}$ layers with $\mathrm{x}$ ranging from 0.003 to 0.33 by adjusting the total implanted $\mathrm{O}$ dose and the energy fluence

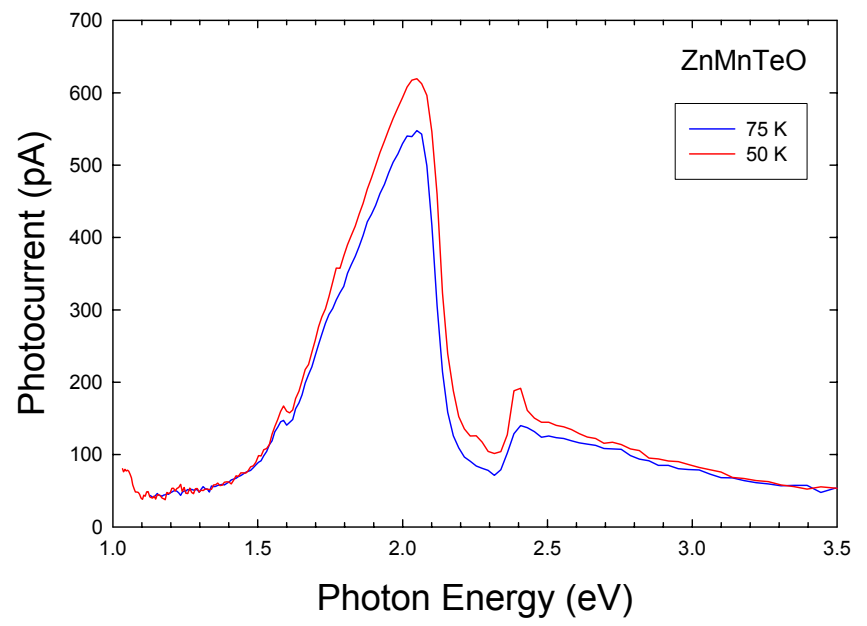

Figure 2. Photocurrent from $\mathrm{ZnMnTeO}$ synthesized by PLM at a fluence of $0.3 \mathrm{~J} / \mathrm{cm}^{2}$. 
of the PLM process.

Photoconductivity experiments were also performed on a $\mathrm{ZnMnOTe}$ sample synthesized by $\mathrm{O}^{+}$implantation followed by PLM with $0.3 \mathrm{~J} / \mathrm{cm}^{2}$ to investigate whether charge carriers are mobile in both conduction bands of this multiband system. A front contact geometry was used. Fig. 2 shows photocurrent response at both $E_{\text {- }}$ and $E_{+}$showing that mobile charge carriers can be excited at both transitions (this is a requirement for proper functioning of a multiband solar cell). We point out that the data is not normalized to the overall spectral distribution which is determined by the grating efficiency and the wavelength-dependent lamp intensity. We tentatively attribute the weaker PC signal in the $E_{+}$region to a stronger surface recombination effect due to shorter penetration depth of the incident light.

Fig. 3 shows a schematics of the calculated energy band structure for the case of $\mathrm{Zn}_{0.88} \mathrm{Mn}_{0.12} \mathrm{O}_{\mathrm{x}} \mathrm{Te}_{1-\mathrm{x}}$ alloy (with $\mathrm{x} \sim 0.024$ ) based on our $\mathrm{PR}$ and photoconductivity results. A narrow band, $E_{-}$of $\mathrm{O}$ derived extended states is separated from the conduction band by about $0.7 \mathrm{eV}$. Three types of optical transitions are possible in this band structure; (1) the transitions from the valence band to the $E_{+}$subband with the absorption edge at $E_{V+}=E_{+}(\mathrm{k}=0)-E_{V}(\mathrm{k}=0)=2.56 \mathrm{eV},(2)$ transitions from the valence band to $E_{-}$subband with the edge at $E_{V_{-}}=E_{-}(\mathrm{k}=0)-E_{V}(\mathrm{k}=0)=1.83 \mathrm{eV}$ and (3) the low energy transitions from $E_{-}$to $E_{+}$with the absorption edge at $E_{-}+=E_{+}(\mathrm{k}=0)-E_{-}(\mathrm{k}=0)=0.73 \mathrm{eV}$. The three absorption edges span much of the solar spectrum, demonstrating that these alloys are good candidates for the multi-band semiconductors envisioned for high efficiency photovoltaic devices.

As a first step towards the realization of a single junction IBSC, we attempt to form an ntype ZnMnOTe layer by co-implanting $\mathrm{Cl}$ and $\mathrm{O}$ in p-type $\mathrm{ZnMnTe}$ crystals $\left(\mathrm{p} \sim 10^{15} \mathrm{~cm}^{-3}\right)$ followed by PLM. It has been well known that ZnTe is nominally p-type. In ZnMnOTe HMAs, because of the $\mathrm{O}$-induced modification in the conduction, we expect that n-type doping can be achieved [21]. Rectifying behavior is observed in this structure as shown in the left panel of Fig. 4. The rectifying behavior indicates that $\mathrm{Cl}$ is active as a n-type dopant and a p-n junction is formed. The right panel shows the photovoltage of the same structure as a function of incident photon energy. Increases in photovoltage at $1.7 \mathrm{eV}$ corresponding to the $E_{-}$edge and at $2.2 \mathrm{eV}$ corresponding to the substrate $\mathrm{ZnMnTe}$ are observed.

To further evaluate the suitability of our three-band semiconductor for solar cell applications we have calculated the solar cell power conversion efficiency for the material with the electronic band structure shown in Fig. 3. The calculations are based on the implementtation of the detailed balance theory [21] to the case of a three band semiconductor [4,5]. Even for this non-optimal band gap configuration we calculate an ideal power conversion efficiency of $45 \%$, which is higher than the ideal efficiency of any solar cell based on a single junction in a single-gap semiconductor and is comparable to the efficiency of double-junction cells.

The great advantage of our material system is the alloy composition provides a means for 

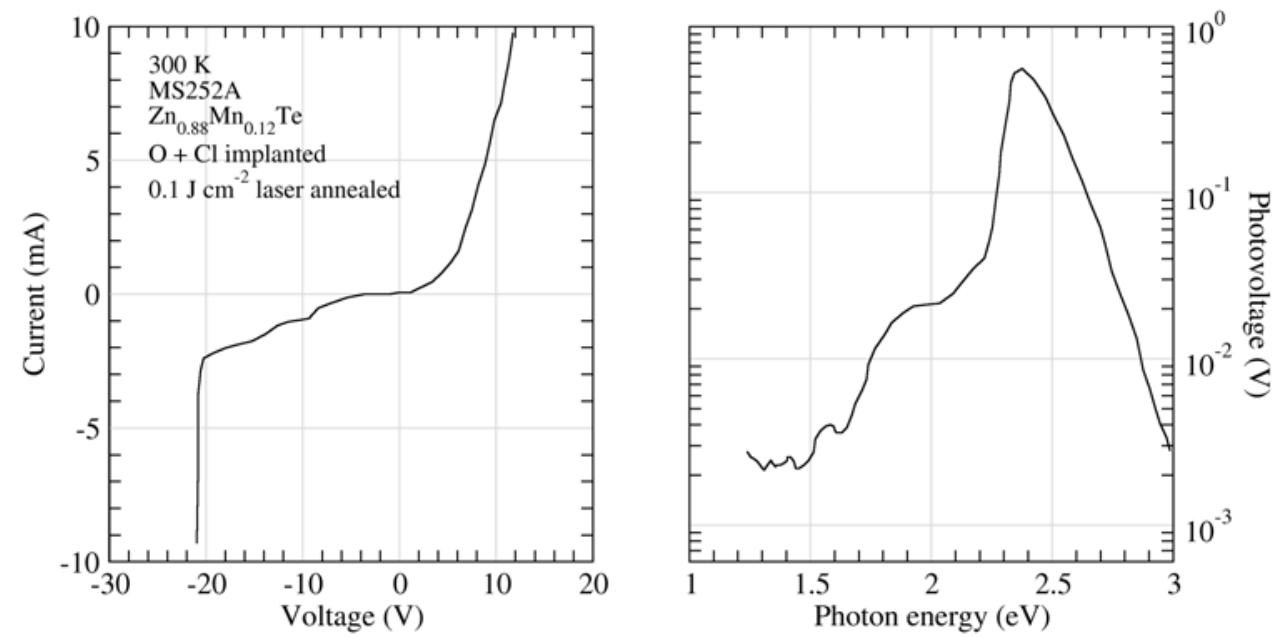

Figure 4. The left panel shows the current-voltage (I-V) measurement on a $\mathrm{Cl}+\mathrm{O}$ implanted p-type ZnMnTe substrate followed PLM with energy fluence of $0.1 \mathrm{~J} / \mathrm{cm}^{2}$. The right panel shows the photovoltage of the same structure as a function of incident photon energy.

varying the three optical transition energies in order to optimize solar cell performance. Fig. 5 shows the calculated solar cell power conversion efficiency for a 3-band $\mathrm{Zn}_{0.88} \mathrm{Mn}_{0.12} \mathrm{O}_{\mathrm{x}} \mathrm{Te}_{1-\mathrm{x}}$ alloy with varying $\mathrm{O}$ content. For example, increasing $\mathrm{x}$ to $\sim 0.05$ would increase the gap between $E_{+}$and $E_{-}$to $1 \mathrm{eV}$ and lead to a three band semiconductor with an optimum efficiency of $56 \%$. Also, changing the Mn content provides another way to vary the band structure for further optimization of solar cell performance.

In addition, we note that other HMAs are also suitable candidates for IBSCs provided that the localized level ( $\mathrm{O}$ in II-VI or $\mathrm{N}$ in III-V) lies below the conduction band of the matrix. A promising system is the $\mathrm{GaN}_{\mathrm{x}} \mathrm{As}_{1-\mathrm{x}-\mathrm{y}} \mathrm{P}_{\mathrm{y}}$ with $\mathrm{y}$ in the range of $0.3-0.5$ where the $\mathrm{N}$ level lies below the conduction band minimum of $\mathrm{GaAs}_{1-\mathrm{y}} \mathrm{P}_{\mathrm{y}}$.

\section{CONCLUSION}

In conclusion we have synthesized $\mathrm{Zn}_{1-}$ ${ }_{y} \mathrm{Mn}_{\mathrm{y}} \mathrm{O}_{\mathrm{x}} \mathrm{Te}_{1-\mathrm{x}}$ alloys by $\mathrm{O}^{+}$-implantation into single crystal $\mathrm{Zn}_{1-\mathrm{y}} \mathrm{Mn}_{\mathrm{y}} \mathrm{Te}$ followed by pulsed laser melting. Alloys with up to 3\% substitutional O mole fraction in the Te sublattice have been achieved. Optical transitions corresponding to the both the lower $\left(E_{-}\right)$and upper $\left(E_{+}\right)$conduction subbands resulting from the anticrossing interaction between the localized $\mathrm{O}$ states and the extended conduction states are clearly observed in these dilute II-VI oxides. We demonstrate that these alloys fulfil the criteria for three band semiconductor that has been proposed as a means of making high efficiency, single-junction intermediate band solar cells.

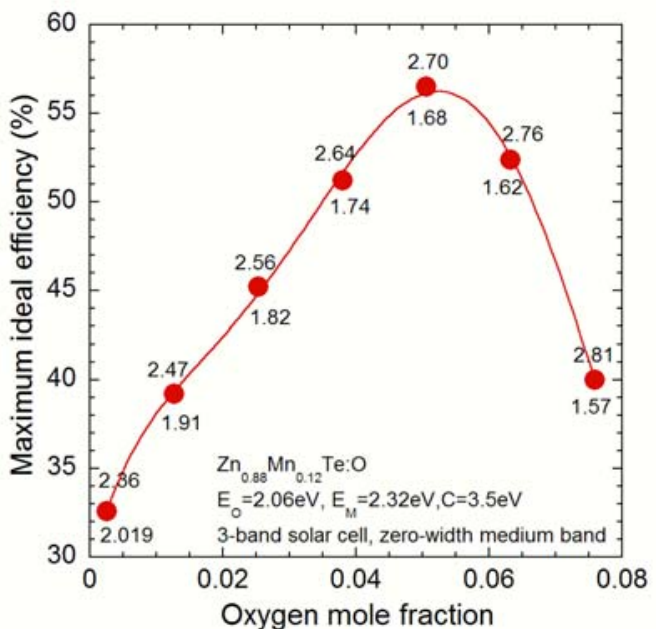

Figure 5: The calculated power conversion efficiency for a solar cell fabricated from a $\mathrm{Zn}_{0.88} \mathrm{Mn}_{0.12} \mathrm{O}_{\mathrm{x}} \mathrm{Te}_{1-\mathrm{x}}$ alloy as a function of $\mathrm{O}$ content. The solid line is an empirical polynomial fit of the calculated data. 


\section{ACKNOWLEDGMENTS}

This work is supported by the Director's Innovation Initiative Program, National Reconnaissance Office and by the Director, Office of Science, Office of Basic Energy Sciences, Division of Materials Sciences and Engineering, of the U.S. Department of Energy under Contract No. DEAC03-76SF00098.

\section{REFERENCES}

1. P. K. Chiang, J. H. Ermer, W. T. Nishikawa, D. D. Krut, D. E. Joslin, J. W. Eldredge, B. T. Cavicchi, J. M. Olson, Proc. 25th IEEE Photovoltaic Specialists Conference (IEEE New York, 1996) p. 183.

2. S. R. Kurtz, D. Myers, J. M Olson, Proc. 26th IEEE Photovoltaic Specialists Conf., (IEEE, New York, 1997) p 875.

3. M. Wolf, Proc. IRE 48, 1246 (1960).

4. A. Luque, A. Marti., Phys. Rev. Lett. 78, 5014 (1997).

5. A. S. Brown, M. A. Green and R. P. Corkish, Physica E 14, 121, (2002).

6. L. Cuadra, A. Marti, and A. Luque, Thin Solid Films 451-452, 593 (2004).

7. W. Shan, W. Walukiewicz, J. W. Ager III, E. E. Haller, J. F. Geisz, D. J. Friedman, J. M. Olson, and S. R. Kurtz, Phys. Rev. Lett. 82, 1221(1999).

8. W. Walukiewicz, W. Shan, K. M. Yu, J. W. Ager III, E. E. Haller, I. Miotlowski, M. J. Seong, H. Alawadhi, and A. K. Ramdas, Phys. Rev. Lett. 85, 1552 (2000).

9. J. Wu, W. Shan and W. Walukiewicz, Semicond. Sci. Tech. 17, 860 (2002).

10. see for example, Semiconductor Science and Technology 17, 2002, Special Issue: III-N-V Semiconductor Alloys.

11. K. M. Yu, W. Walukiewicz, J. Wu, W. Shan, and J. W. Beeman, M. A. Scarpulla, O. D. Dubon, and P. Becla, J. Appl. Phys.95, 6232 (2004).

12. K. M. Yu, W. Walukiewicz, J. Wu, W. Shan, and J. W. Beeman, M. A. Scarpulla, O. D. Dubon, and P. Becla, Phys. Rev. Lett. 91, 246203 (2003)

13. C. W. White and P. S. Peercy, eds., Laser and Electron Beam Processing of Materials (Academic Press, New York, 1980).

14. J. S. Williams in Laser Annealing of Semiconductors, J. M. Poate and J. W. Mayer, eds., p. 385 (Academic Press, New York, 1982).

15. K. M. Yu, W. Walukiewicz, M. A. Scarpulla, O. D. Dubon, J. Jasinski, Z. Liliental-Weber, J. Wu, J. W. Beeman, M. R. Pillai, and M. J. Aziz, J. Appl. Phys.94, 1043 (2003).

16. M. A. Scarpulla, K.M. Yu, O. Monteiro, M. Pillai, M.C. Ridgway, M.J. Aziz, and O.D. Dubon, Appl. Phys. Lett. 82, 1251 (2003).

17. D. E. Aspnes, Surf. Sci. 37, 418 (1973).

18. M. J. Seong, H. Alawadhi, I. Miotkowski, A. K. Ramdas and S. Miotkowska, Phys. Rev. B60, R16275(1999).

19. W. Shan, W. Walukiewicz, J.W. Ager III, K. M. Yu, J. Wu, E. E. Haller, Y. Nabetani, T. Mukawa, Y. Ito, and T. Matsumoto, Appl. Phys. Lett. 83, 299 (2003).

20. W. Shockley and H. J. Queisser,. J. Appl. Phys. 32, 510 (1961).

21. K. M. Yu, W. Walukiewicz, W. Shan, J. W. Ager III, J. Wu, E. E. Haller, J. F. Geisz, D. J. Friedman, J. M. Olson, and Sarah R. Kurtz, Phys. Rev. B61, R13337 (2000). 